\title{
The Relationship between the Weight of the Placenta and Birth Weight of Term Neonate Delivered in Alex Ekwueme Federal University Teaching Hospital Abakaliki, Nigeria
}

\author{
Ayodele Adegbite Olaleye, Johnbosco Ifunanya Nwafor* ${ }^{\circledR}$, Ikenna Chidi Ebere, \\ Chukwunenye Chukwu Ibo, Darlington-Peter Chibuzor Ugoji, Nobert Chuka Obi, \\ Sunday Uchenna Asogwa, Alfred Nnabugwu Adiele \\ Department of Obstetrics and Gynaecology, Alex Ekwueme Federal University Teaching Hospital, Abakaliki, Nigeria \\ Email: *nwaforjohnbosco97@gmail.com
}

How to cite this paper: Olaleye, A.A., Nwafor, J.I., Ebere, I.C., Ibo, C.C., Ugoji, D.-P.C., Obi, N.C., Asogwa, S.U. and Adiele, A.N. (2019) The Relationship between the Weight of the Placenta and Birth Weight of Term Neonate Delivered in Alex Ekwueme Federal University Teaching Hospital Abakaliki, Nigeria. Advances in Reproductive Sciences, 7, 82-93.

https://doi.org/10.4236/arsci.2019.74010

Received: July 27, 2019

Accepted: September 22, 2019

Published: September 25, 2019

Copyright $\odot 2019$ by author(s) and Scientific Research Publishing Inc. This work is licensed under the Creative Commons Attribution International License (CC BY 4.0).

http://creativecommons.org/licenses/by/4.0/ (c) (i) Open Access

\begin{abstract}
Background: The placenta is in a key position to determine the final birth weight of foetuses because adequate placental function is necessary for delivery of nutrients, oxygen, and hormones to the foetus. The relationship between the placental weight and birth weight of the neonates has been reported from several publications but such reports from Abakaliki are lacking in literature. Aim: To determine the relationship between the placental weight and birth weight of the neonates delivered at term at the Alex Ekwueme Federal University Teaching Hospital Abakaliki. Materials and Method: It was a retrospective study conducted between 1st January 2015 and 31st December 2015. The statistical analysis was done using Epi Info software version 7.2.1 (CDC Atlanta Georgia). Result: The mean birth weight was $3344 \pm 488 \mathrm{~g}$ while the mean placental weight was $617 \pm 78 \mathrm{~g}$. The mean placental weight to birth weight ratio (PBWR X 100) was $19.94 \% \pm 4.2 \%$. Increase in birth weight of the neonate was associated with a corresponding increase in placental weight with a strong statistical significance level $(P=0.968)$. One thousand nine hundred and five (90.5\%) patients had PBWR that ranged between $15 \%$ and $24 \%$, which was associated with good immediate neonatal outcome. The placental weight to birth weight ratio outside this range was associated with increased admission into NICU and perinatal mortality at an odd ratio of 0.5844 and a statistical significance level $(\mathrm{P})$ of 0.0036 . Conclusion: There is a positive correlation between placental weight and birth weight of the neonate. Knowing the PBWR at birth may help to know the foetus at risk of immediate poor neonatal outcome in order to expedite actions to prevent possible poor perinatal outcome.
\end{abstract}




\section{Keywords}

Placenta, Weight, Birth Weight, Neonate, Abakaliki

\section{Introduction}

The human placenta develops with the principal function of providing nutrients and oxygen to the foetus [1]-[20]. Adequate foetal growth and subsequent normal birth weight depend on the efficient delivery of nutrients from the mother to the foetus via normally functioning utero-placental organ [2]-[10]. It is clear that normal development of placenta during gestation is necessary for support of a healthy foetus [1] [2]. The average weight of placenta at birth is $508 \mathrm{~g}$ [3]. However, methods of measurement vary widely particularly due to differences in placental preparations before weighing [4].

Placental weight and its relationship to infant size at birth have been studied for more than a century. Past studies indicated that placental weight was associated with pregnancy outcome. High placenta weight was associated with a poor perinatal outcome, a low Apgar score, respiratory distress syndrome and perinatal death; whereas a low placental weight was associated with medical complications in the mother [5] [6]. It has also been reported that altered growth of the placenta was a predictor of maternal medical diseases including cardiovascular disease, hypertension and diabetes mellitus [7] [9] [21]. Other factors such as race and socioeconomic status also affect the placental weight [22]-[27].

Careful examination of the placenta can provide insight regarding the in-utero environment of the foetus before delivery. There is a positive correlation between foetal weight and placental weights [27]. The standard method of weighing the placenta, after trimming the placental disk off membranes and umbilical cord, may also merit simplification. Leary et al. suggested that the foetal weight/placental weight correlation does not change when placentas are weighed trimmed compared to when they are weighed untrimmed [28]-[35]. The placenta can be weighed with membranes and cord attached, but the standard approach since its proposal by Benirschke in the early 1960s is to weigh the placenta after the extra placental membranes and the umbilical cord are trimmed from the disk [29]. This limits the measurement to the weight of the placental disk, the actual nutrient exchanging part of the placenta. However, Leary et al. suggested that trimmed and untrimmed placental weights are exchangeable, based on their high correlation [34] [35]. Paucity of report in literature on placental weight and its relationship to the weight of the neonate at birth in Abakaliki informed this study. Therefore the aim of this study was to determine the relationship between placenta weight and birth-weight of neonate in our hospital.

\section{Materials and Method}

Study area: Alex Ekwueme Federal University Teaching Hospital (formerly 
known as Federal Teaching Hospital) Abakaliki is a tertiary hospital within Abakaliki metropolis. The hospital is made up of ten clinical departments; Obstetrics and Gynaecology, Paediatrics, Medicine, Surgery, Psychiatry, Community Health, Family Medicine, Ophthalmology, ENT and Anaesthesiology. Department of Obstetrics and Gynaecology is one of the ten clinical departments in the hospital, it has ten teams with each comprising consultants, senior registrars, registrars, senior house officers and house officers. The department runs gynecological clinics, preconception, antenatal, intrapartum, and postnatal services. It is also a referral centre to the surrounding maternities and hospitals and also receives referral from surrounding states: Cross Rivers, Enugu, and Benue states.

Study design: This was a retrospective study conducted at Alex Ekwueme Federal University Teaching Hospital, Abakaliki. The study cohorts were women delivered at term ( 37 to 42 weeks) between 1st January 2013 and 31st December 2015. A pre-designed proforma were used to extract patients' information on gestational age at delivery (in weeks), parity, mode of delivery, foetal birth weight, placental weight, foetal gender, and presence or absence of maternal medical diseases. The inclusion criteria included that the pregnancy must be term and singleton. Exclusion criteria included retained placenta, multiple pregnancies and morbidly adherent placentae.

Data analysis: Data analysis was done using Epi Info software (7.2.1 CDC Atlanta Georgia) and statistical analysis performed using one way analysis of variance. The results were expressed as frequency tables, percentages, pie charts, mean and standard deviation. The relationships between categorical data were analyzed using $\mathcal{X}^{2}$, with a P-value of 0.05 considered statistically significant and correlation coefficients were calculated using Pearson's formula. Odd ratios were also calculated.

Ethical consideration: Ethical approval for the study was sought and obtained from the Research and Ethical Committee of the Alex Ekwueme Federal University Teaching Hospital, Abakaliki and the study duration approved for the study was 1 year.

\section{Results}

Out of a total of 2417 total deliveries within the study period, 2215 mothers met the inclusion criteria constituting $91.6 \%$ of deliveries during the period. The remaining $202(8.4 \%)$ women were excluded from the study due to incomplete documentation in their hospital notes. Two thousand one hundred and six hospital folders were retrieved constituting $95.07 \%$ folder retrieval rate. The placental birth weight ratios (PBWR) were calculated by dividing placenta weight by birth weight of the neonate and multiplied by 100 .

Table 1 shows the maternal characteristics, perinatal outcome and placental birth weight ratio. The ages of the patients ranged from 16 to 42 years with a mean of $29.11 \pm 5.3$ years. The relationship between increasing maternal age and placenta weight ratio was not statistically significant $(\mathrm{P}=0.283)$. The mean parity 
Table 1. Relationship between maternal age and booking status with placenta birth weight ratios.

\begin{tabular}{cccc}
\hline Characterictics & Number (\%) & PBWR (\%) & P value \\
\hline Age range & & & \\
$15-19$ & $37(1.76)$ & 20.05 & \\
$20-24$ & $306(14.53)$ & 19.22 & 0.283 \\
$25-29$ & $785(37.27)$ & 19.98 & $($ NS) \\
$30-34$ & $742(35.23)$ & 19.95 & \\
$35-39$ & $193(9.16)$ & 18.76 & \\
$40-44$ & $43(2.04)$ & 20.24 & 0.2503 \\
Total & 2106 & & $($ NS) \\
Booking status & & 19.98 & \\
Booked & $1698(80.63)$ & 19.12 & \\
Unbooked & $408(19.37)$ & & \\
Total & 2106 & & \\
\hline
\end{tabular}

NS = not statistically significant.

of the subject was $1.79 \pm 3$ with a range of $0-9)$. One thousand, six hundred and ninety eight patients (80.63\%) were booked while 408 (19.37\%) were unbooked. The relationship between booking status of the patient and placenta weight ratio is not statistically significant $(\mathrm{P}>0.05)$.

The average gestational age at delivery was $39.5 \pm 3.8$ weeks with a range of $37-42$ weeks as shown in Table 2 . The relationship between increasing gestational age and placenta birth weight ratio was statistically significant $(\mathrm{P}<$ 0.0001).

One thousand, eight hundred and eighteen patients (86.30\%) had spontaneous vertex delivery while 288 (13.70\%) of the patients had caesarean section (Table 3 ). The relationship between mode of delivery and placenta weight ratio is not statistically significant $(\mathrm{P}>0.05)$. The mean birth weight and placenta weight from caesarean section were comparable to those from vaginal delivery (3444 g vs $3320 \mathrm{~g}$ ) and (628.7 g vs $603.98 \mathrm{~g})$, respectively and was not statistically significant at $(\mathrm{P}>0.05)$. One hundred and one fetuses, constituting $4.8 \%$ of fetuses suffered perinatal mortality.

The mean neonatal birth weight was $3344 \pm 488 \mathrm{~g}$ with a range of $2200-5100$ $\mathrm{g}$ while the average placental weight was $617 \pm 72 \mathrm{~g}$ with a range of $400-1300 \mathrm{~g}$. The mean PBWR was $19.94 \pm 4.2$ with a range of $14.28-38.22$ as depicted in Table 4. The PBWR decreases from 37 weeks to 39 weeks gestation after which it started increasing up to 42 weeks gestation.

Both the placental and neonatal birth weights increase with advancing gestation (with the latter increasing more than the former). This relationship is depicted in Figure 1 and Figure 2. The correlation coefficient ( $r$ ) between the placental weight and foetal birth weight was 0.968 (reflecting a strong positive correlation). 
Table 2. Gestational age and placenta birth weight ratio.

\begin{tabular}{cccc}
\hline Gestationa age & Number (\%) & PBWR (\%) & P value \\
\hline 37 & $222(10.54)$ & 21.15 & \\
38 & $746(35.42)$ & 19.92 & \\
39 & $481(22.84)$ & 19.70 & $<0.0001$ \\
40 & $466(22.13)$ & 19.96 & \\
41 & $173(8.21)$ & 20.00 & \\
42 & $18(0.86)$ & 22.93 & \\
Total & 2106 & & \\
\hline
\end{tabular}

Table 3. Mode of delivery and perinatal outcome with placenta birth weight ratio.

\begin{tabular}{cccc}
\hline Characteristics & Number (\%) & PBWR (\%) & P value \\
\hline Mode of delivery & & & \\
SVD & $1818(86.30)$ & 19.86 & 0.3092 \\
CS & $288(13.70)$ & 18.98 & (NS) \\
Total & 2106 & & \\
Foetal outcome & & 19.58 & 0.3705 \\
Alive & $2005(95.20)$ & 19.26 & $(\mathrm{NS})$ \\
Dead & $101(4.80)$ & & \\
Total & 2106 & & \\
\hline
\end{tabular}

SVD: spontaneous vertex delivery; CS: caesarean section; NS: not statistically significant.

Table 4. Mean neonatal birth weight (g), placental weight (g), and placental-birth weight ratio by gestational age at birth.

\begin{tabular}{ccccc}
\hline GA at Birth & Number (\%) & BW Mean (SD) & PW mean (SD) & PBWR (SD) \\
\hline 37 & $189(8.97)$ & $3219(300)$ & $601(87)$ & $21.15(1.0)$ \\
38 & $850(40.38)$ & $3283(139)$ & $613(83)$ & $19.92(2.6)$ \\
39 & $457(21.69)$ & $3481(240)$ & $663(73)$ & $19.70(1.4)$ \\
40 & $450(21.37)$ & $3428(149)$ & $684(39)$ & $19.96(1.3)$ \\
41 & $144(6.84)$ & $3573(334)$ & $705(12)$ & $20.00(1.2)$ \\
42 & $16(0.75)$ & $3613(336)$ & $728(11)$ & $22.93(3.5)$ \\
\hline
\end{tabular}

GA: gestational age; SD: standard deviation; BW: birth weight; PW: placenta weight; PBWR: placenta birth weight ratio.

Table 5 shows the distribution of mean birth weight and placental weight by parity. Majority of the patient seen $(92.12 \%)$ have low parity between $0-4$, while $7.88 \%$ of the patients seen were grand multiparous women. There is a slight increase in mean placental weight with increasing parity up-to to the fifth parity, but there was a decrease at parity of six and above. However, increasing parity did not have any significant effect on placenta birth-weight ratio $(\mathrm{P}$ value $=$ 0.0329). 


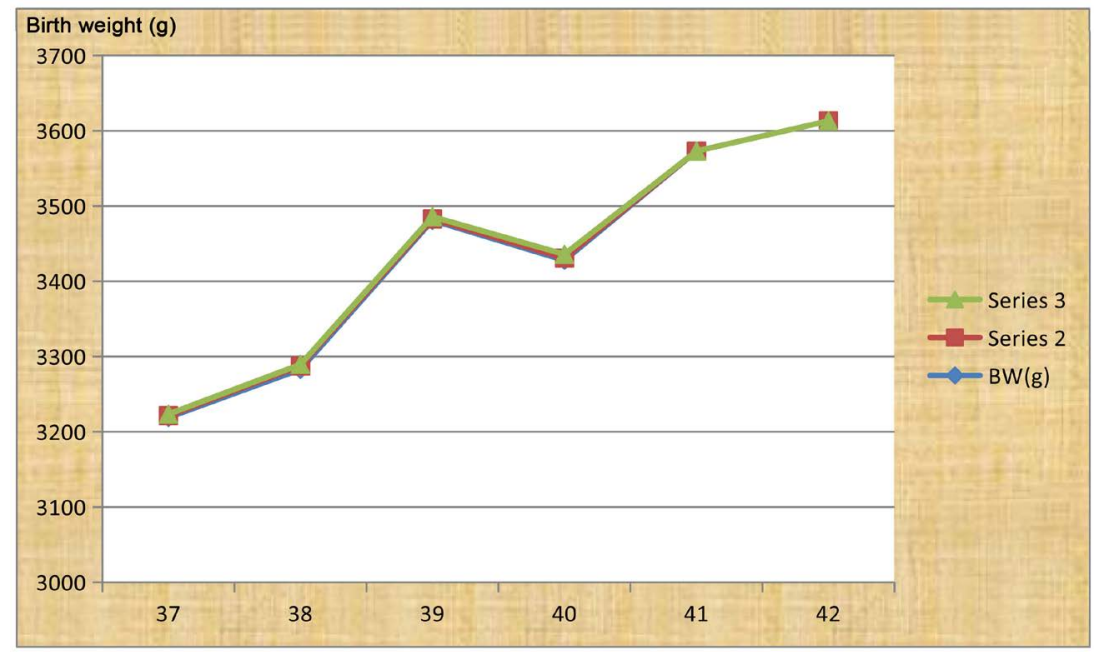

Figure 1. Correlation between the mean birth weight and gestational age.

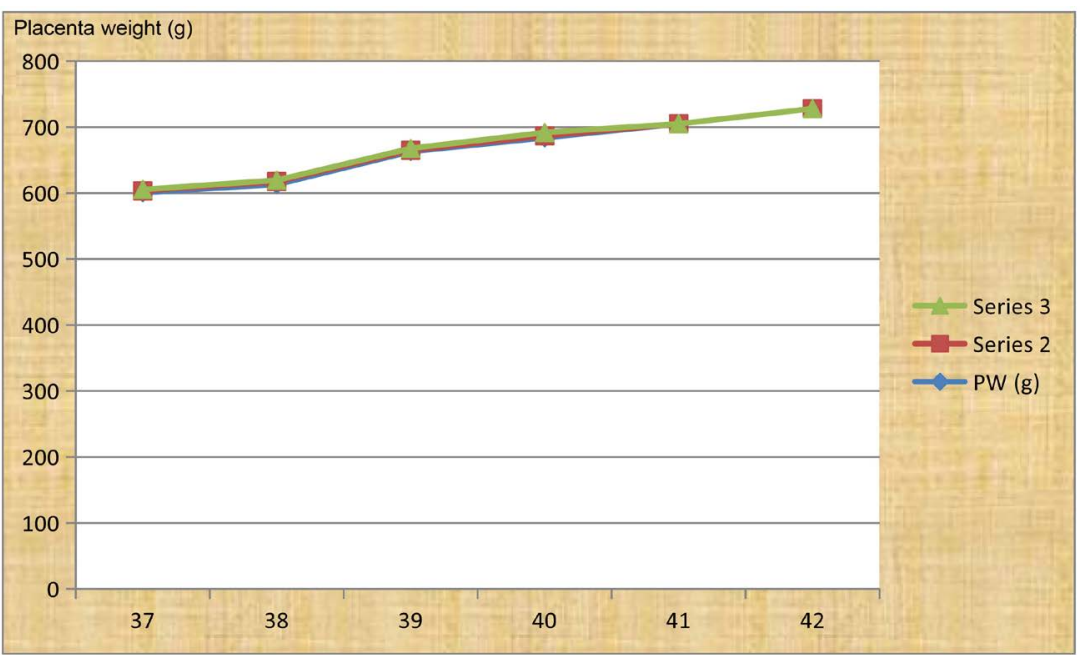

Figure 2. Correlation between mean placenta weight and gestational age.

Table 5. Mean birthweight and placental weight by parity.

\begin{tabular}{cccccc}
\hline Parity & Frequency & Percentage & BW mean (SD) & PW mean (SD) & PBWR (SD) \\
\hline 0 & 547 & 25.97 & $3282(233)$ & $682(63)$ & $18.46(1.4)$ \\
1 & 594 & 28.21 & $3381(164)$ & $693(92)$ & $20.55(4.1)$ \\
2 & 371 & 17.62 & $3317(210)$ & $696(73)$ & $19.52(1.5)$ \\
3 & 253 & 12.01 & $3486(252)$ & $702(86)$ & $20.64(1.6)$ \\
4 & 175 & 8.31 & $3373(251)$ & $692(62)$ & $19.98(1.6)$ \\
5 & 65 & 3.09 & $3478(391)$ & $699(53)$ & $20.05(0.8)$ \\
6 & 58 & 2.75 & $3231(409)$ & $681(45)$ & $20.37(7.4)$ \\
7 & 18 & 0.86 & $3550(669)$ & $622(24)$ & $17.75(2.1)$ \\
8 & 18 & 0.86 & $3280(453)$ & $650(29)$ & $19.63(2.5)$ \\
9 & 7 & 0.32 & $3200(400)$ & $640(50)$ & $24.00(4.5)$ \\
\hline
\end{tabular}

BW means birth weight; PW means placenta weight; PBWR means placenta birth weight ratio; P value = 0.0329 indicating a positive but weak correlation. 
The sex ratio (male to female) was 1.1:1. The distribution of birth weight by gender is shown in Table 6. The mean birth weight of male babies $(3389 \mathrm{~g})$ was higher than that of their female counterpart (3304 g) and the placenta birthweight ratio for male was higher than female. However, these were not statistically significant $(\mathrm{P}>0.05)$.

Table 7 depicts the distribution of mean placental birth weight ratio in relation to maternal medical conditions. The study showed that maternal medical conditions have no effect on mean placental birth weight ratio $(\mathrm{P}=0.063)$.

Table 8 showed the relationship between Placenta and Birth weight ratio and the immediate fetal outcome. One thousand, nine hundred and five (90.5\%) patients had PBWR that ranged between 15 and 24. Twenty five percent (25\%) of babies delivered with PBWR of less than 15 were admitted into NICU for moderate to severe birth asphyxia and $40 \%$ of them suffered perinatal death. Also, $30.9 \%$ of babies with PBWR that ranged between 25 and 29 were admitted into NICU and $11.1 \%$ of them suffered perinatal death. For babies with PBWR of 30 $34,54.45 \%$ of them were admitted into NICU whereas remaining $45.45 \%$ suffered perinatal mortality. All the babies with PBWR of greater than 35 suffered early perinatal mortality. The correlation coefficient (r) between the PBWR and immediate neonatal outcome was 0.7104 (reflecting a positive correlation).

Table 6. Mean birth weight (g) and placental weight ( $\mathrm{g}$ ) by foetal gender.

\begin{tabular}{cccccc}
\hline Fetal sex & Number & Percentage & $\begin{array}{c}\text { BW } \\
(\text { SD })\end{array}$ & $\begin{array}{c}\text { PW } \\
(\text { SD })\end{array}$ & $\begin{array}{c}\text { PBWR } \\
(\text { SD })\end{array}$ \\
\hline Male & 1104 & 52.46 & $3389(158)$ & $689(48)$ & $20.53(65)$ \\
Female & 1002 & 47.54 & $3304(128)$ & $693(64)$ & $19.97(223)$ \\
Total & 2106 & 100 & & & P value $=0.598$ \\
\hline
\end{tabular}

$\mathrm{SD}=$ standard deviation; $\mathrm{BW}=$ birth weight $\mathrm{PW}=$ placenta weight $\mathrm{PBWR}=$ placenta birth weight ratio; $\mathrm{P}$ value $=0.598$.

Table 7. Placental weight (g) in relation to maternal medical conditions.

\begin{tabular}{cccc}
\hline Medical Condition & Frequency & Percentage & $\begin{array}{c}\text { Mean PBWR } \\
\text { (SD) }\end{array}$ \\
\hline Normal & 1942 & 92.21 & $18.87(6.3)$ \\
Hypertension & 84 & 3.99 & $20.80(3.4)$ \\
HIV Positive & 27 & 1.29 & $19.19(2.8)$ \\
Rheusu Negative & 21 & 0.99 & $17.95(3.8)$ \\
Eclampsia & 19 & 0.90 & $21.11(3.3)$ \\
Diabetes Mellitus & 8 & 0.38 & $18.42(2.3)$ \\
Asthma & 5 & 0.24 & $20.20(3.9)$ \\
Total & 2106 & 100 & P value $=0.063$
\end{tabular}


Table 8. Placenta birth weight ratio (PBWR) in relation to immediate fetal outcome.

\begin{tabular}{ccccc}
\hline \multicolumn{2}{c}{ PBWR (\%) } & \multicolumn{3}{c}{ Fetal Outcome } \\
\hline Range (\%) & Number & $\begin{array}{c}\text { Alive and } \\
\text { Normal (\%) }\end{array}$ & $\begin{array}{c}\text { Alive with NICU } \\
\text { Admission (\%) }\end{array}$ & $\begin{array}{c}\text { Perinatal } \\
\text { Mortality (\%) }\end{array}$ \\
\hline $10-14$ & 20 & $7(35.0)$ & $5(25.0)$ & $8(40.0)$ \\
$15-19$ & 724 & $657(90.7)$ & $25(3.4)$ & $43(5.9)$ \\
$20-24$ & 1181 & $1139(96.4)$ & $23(1.9)$ & $19(1.6)$ \\
$25-29$ & 162 & $94(58.0)$ & $50(30.9)$ & $18(11.1)$ \\
$30-34$ & 11 & 0 & $6(54.54)$ & $5(45.45)$ \\
$35-39$ & 8 & 0 & 0 & $8(100)$ \\
Total & 2106 & 1897 & 109 & 101 \\
\hline
\end{tabular}

PBWR = placenta birth weight ratio; NICU = neonatal intensive care unit. The correlation coefficient $(r)$ between the PBWR and immediate neonatal outcome was 0.7104 (reflecting a positive correlation).

\section{Discussion}

Placental weight and birth weight of the neonate are widely available measures. The ratio of these two variables is a useful marker of foetal nutrition and utero-placental function. The mean placental weight of $617 \mathrm{~g}$ in this study is comparable to $623 \mathrm{~g}$ reported in North-central Nigeria but lower than $643 \mathrm{~g}$ reported in Western Europe [28] [29]. However, it is more than 588 and 590 g reported in Northern Nigeria and Ukraine respectively [6] [30]. The variations in the mean weight of the placenta may be due to variations in the methodology of preparing and weighing the placenta together with cord clamping time [5] [6]. It has also been reported that ethnicity may affect the placental weight [6]. The mean birth weight of the neonate in this study (3344 g) is lower than $3425 \mathrm{~g}$ and $3382 \mathrm{~g}$ reported in Ukraine and Western Europe, respectively; but higher than $3065 \mathrm{~g}$ and 3275 g reported in two different studies in Northern Nigeria [6] [29] [30] [33]. These differences in mean birth weight may be due to altitude, race, genetics, maternal nutrition and maternal diseases [6].

The mean PBWR of $19.94 \%$ in this study is similar to $20.0 \%$ and $20.24 \%$ reported in Western Europe and North-central Nigeria but higher than $13.9 \%$ and 18.2\% reported in Ukraine and Northern Nigeria, respectively [6] [28] [29] [30]. The positive correlation between the placental weight and neonatal birth weight noted in this study has been observed by previous authors [6] [30] [33]. The decline in PBWR with increasing gestational age at term observed in the present study has been reported by previous authors [6] [34] [35]. An abnormally high PBWR (i.e. low neonatal weight relative to the placental weight) is thought to indicate an abnormal placenta with impaired function as in human immune deficiency virus infection, obesity, maternal anaemia, cigarette smoking and low socioeconomic status [6] [34] [35]. As shown in this study, Infants with such abnormal ratios are at increased risk of NICU admission and perinatal death, and this correlates with previous studies [5] [6]. 
A placenta weight to birth weight Ratio (PBWR) range of $15.0 \%$ to $24.9 \%$ is optimal for foetal survival according to this study. Conversely, an abnormally low PBWR $(<15.0 \%)$ indicates foetuses with presumed reduced placental reserves and carries poor perinatal outcome. Such foetuses tend to show asymmetric growth restriction, suggesting that the small placenta limits optimal foetal growth with poor immediate neonatal outcome and this was in accordance with previous studies [5] [6]. From this study, PBWR of lower than 15\% and higher than $24 \%$ are associated with poor neonatal outcome. This observation is slightly different from what was earlier reported by Chandrakant et al. [5]. Chandrakant et al. reported that a PBWR of $\leq 15.99 \%$ was low, $16 \%-19.9 \%$ was normal and $\geq 20 \%$ was high and that PBWR of $\leq 15.99 \%$ and $\geq 20 \%$ are associated with poor neonatal outcome. This observed difference may be due to differences in placenta preparation. However, both studies agreed that abnormally low and high PBWR are associated with poor perinatal outcome.

The socio-demographical data of patients in this study is comparable to what was reported in the previous studies. The age range of the subjects in this study 16 - 42 years is similar to the age range of 16 - 38 years reported in a previous study done in Sokoto [6]. Just like in the earlier studies, the relationship between maternal age and PBWR is not statistically significant. The mean gestational age in the study (39.5 weeks) is also similar to 39.7 weeks and 39.9 weeks reported in western Europe and North-central Nigeria, respectively, but higher than 38.8 weeks reported in Sokoto [6] [28] [29]. According to this study, the relationship between advancing gestation and PBWR is statistically significant and this is similar to what was reported in the previous studies [6] [28] [29] [30]. Most of the women enrolled for the study were booked patients $(80.63 \%)$ because most of the unbooked patients did not satisfy the inclusion criteria for the study. As shown in this study, booking status has no statistically significant effect on PBWR. The mean birth weight of babies delivered by caesarean section in this study was lower than those delivered vaginally while the placental weight was higher in the former than later. Similar observation had been made in previous studies [6] [31]. Differences in cord clamping time have been suggested to explain these differences, since the umbilical cords are frequently clamped relatively late in vaginal delivery (so as to optimize blood transfer to the fetus) while in caesarean section early clamping of the cord is usually the rule [6]. Furthermore, due to the absence of uterine contractions during caesarean section, the intervillous space in the placenta is more expansive and likely to contain more maternal blood than in vaginal deliveries where maternal blood is squeezed out of the placenta by contraction of the uterus [6] [28]. However, mode of delivery has no significant effect on PBWR.

Relative increase in both placental and neonatal birth weight associated with increasing parity up to Para 5 , then gradual decline in the placenta and neonatal weight from 6th parity upward was similar to what was earlier obtained in central Nigeria [28] but was not in agreement with Azupurua's report that the weight 
of placentae and babies from multiparous women are higher than those primigravid and primiparous women [35].

The limitations of this study include poor record keeping in most of our centres, which makes obtaining information of patient cumbersome. Also, most of the data obtained from this study were gotten from labour record and patients' folders with a lot of individual differences in measurement and recording of patients' information by various cadres of health workers involved. A prospective study that will use limited number of patients with the same researcher and measuring scale is suggested.

\section{Conclusion}

In conclusion, this study has shown that there is a positive correlation between the placental and infant weight. In addition, the ratio of the placenta and foetal weights at term increases with advancing gestational age. Also, sociodemographic data of the mother and maternal medical condition have no statistically significant effect on placenta birth weight ratio. A PBWR of between 15 and 24 is optimal for good immediate neonatal outcome. A PBWR of higher than 24 or lower than 15 is associated with poor perinatal outcome. Therefore, factors causing abnormally high or low PBWR will result in poor immediate perinatal outcome. Recognizing such abnormal value of PBWR will help to expedite actions that will help to prevent poor immediate perinatal outcome.

\section{Conflicts of Interest}

The authors declare no conflicts of interest regarding the publication of this paper.

\section{References}

[1] Suri, S., Muttukrishna, S. and Jauniaux, E. (2013) 2D-Ultrasound and Endocrinologic Evaluation of Placentation in Early Pregnancy and Its Relationship to Fetal Birthweight in Normal Pregnancies and Pre-Eclampsia. Placenta, 34, 727-840. https://doi.org/10.1016/j.placenta.2013.05.003

[2] Azpurua, H., Funai, E.F., Coraluzzi, L.M., Doherty, L.F., Sasson, I.E., Kliman, M., et al. (2010) Determination of Placental Weight Using Two-Dimensional Sonography and Volumetric Mathematic Modeling. American Journal of Perinatology, 27, 151-155. https://doi.org/10.1055/s-0029-1234034

[3] Cunningham, F.G., Leveno, K.J., Bloom, S.L., Hauth, J.C., Gilstrap III, L.C. and Wenstrom, K.D. (2005) Implantation, Embryogenesis and Placental Development. In: Williams Obstetrics, 22nd Edition, McGraw-Hill, New York, 39-90.

[4] Panuganti, P.K. and Boddeti, R.K. (2012) Morphology and Morphometric Anatomy of Placenta. International Journal of Biological and Medical Research, 3, 2165-2168.

[5] Chandrakant, M., Jayalakshmi, M., Hemant, D. and Rajendra, S. (2015) A Study of Placenta Weight and Birth Weight Ratio (PW/BW) and Its Effects on Perinatal Outcome. Indian Journal of Obstetrics and Gynaecology, 2, 1-6.

[6] Panti, A.A., Ekele, B.A., Nwobodo, E.I. and Yakubu, A. (2012) The Relationship between the Weight of the Placenta and Birth Weight of the Neonate in a Nigerian Hospital. Nigerian Medical Journal, 53, 80-84.

https://doi.org/10.4103/0300-1652.103547 
[7] Saeed, I., Qamar, K., Noor, U., Iqbal, I. and Humairaarshad (2011) Foeto-Placental Weight Relationship in Normal Pregnancy and Pre-Eclampsia. Journal of Rawalpindi Medical College, 15, 53-55.

[8] Adeyekun, A.A. and Ikubor, J.E. (2015) Relationship between Two-Dimensional Ultrasound Measurement of Placental Thickness and Estimated Foetal Weight. Sahel Medical Journal, 18, 4-8. https://doi.org/10.4103/1118-8561.152151

[9] Afrakhteh, M., Moeini, A., Taheri, M.S. and Haghighatkhah, R.H. (2013) Correlation between Placental Thickness in the Second and Third Trimester and Foetal Weight. Revista Brasileira de Ginecologia e Obstetrícia, 35, 317-322. https://doi.org/10.1590/S0100-72032013000700006

[10] Gupta, C., Harode, H.A., D’souza, A.S. and Sharma, A. (2015) A Morphological and Morphometric Study of Placenta with Its Clinical Implications. Tropical Journal of Medical Research, 18, 85-88. https://doi.org/10.4103/1119-0388.158400

[11] Salafia, C.M., Zhang, J., Miller, R.K., Charles, A.K., Shrout, P. and Sun, W. (2007) Placental Growth Patterns Affect Birth Weight for Given Placental Weight. Birth Defects Research Part A: Clinical and Molecular Teratology, 79, 281-288. https://doi.org/10.1002/bdra.20345

[12] Salavati, N., Gordijn, S.J., Sovio, U., Zill-E-Huma, R., Gebril, A., Charnock-Jones, D.S., et al. (2018) Birth Weight to Placenta Weight Ratio and Its Relationship to Ultrsonic Measurements, Maternal and Neonatal Outcome: A Prospective Cohort Study of Nulliparous Women. Placenta, 63, 45-52. https://doi.org/10.1016/j.placenta.2017.11.008

[13] Pathak, S., Jessop, F., Hook, L., Sebire, N.J. and Lees, C.C. (2010) Placental Weight, Digitally Derived Placental Dimensions at Term and Their Relationship to Birth Weight. The Journal of Maternal-Fetal \& Neonatal Medicine, 23, 1176-1182. https://doi.org/10.3109/14767051003615434

[14] Reiter, R.J., Tan, D.X., Korkmaz, A. and Rosales-Corral, S.A. (2013) Melatonin and Stable Circadian Rhythms Optimize Maternal, Placental and Foetal Physiology. $\mathrm{Hu}-$ man Reproduction, 20, 293-307. https://doi.org/10.1093/humupd/dmt054

[15] Kiserud, T. and Acharya, G. (2004) The Fetal Circulation. Prenatal Diagnosis, 24, 1049-1059. https://doi.org/10.1002/pd.1062

[16] Mercier, J.S. and Vohr, B.R. (2010) Seven-Month Developmental Outcomes of Very Low Birth Weight Infants Enrolled in a Randomized Controlled Trial of Delayed versus Immediate Cord Clamping. Journal of Perinatology, 30, 11-16. https://doi.org/10.1038/jp.2009.170

[17] Wright, C. and Sibley, C.P. (2011) Placental Transfer in Health and Disease. In: Kay, H., Nelson, M. and Wang, Y.P., Eds., The Placenta: From Development to Disease, John Wiley and Sons, Hoboken, 66. https://doi.org/10.1002/9781444393927.ch9

[18] Kappen, C., Kruger, C., MacGowan, J. and Salbaum, J.M. (2012) Maternal Diet Modulates Placenta Growth and Gene Expression in a Mouse Model of Diabetic Pregnancy. PLoS ONE, 7, e38445. https://doi.org/10.1371/journal.pone.0038445

[19] Pillitteri, A. (2009) Maternal and Child Health Nursing: Care of the Childbearing and Childrearing Family. Lippincott Williams \& Wilkins, Hagerstwon, 202-206.

[20] Reiter, E.O. and Rosenfeld, R.G. (2011) Normal and Aberrant Growth. In: Kronenberg, H.M., Shlomo, M., Polonsky, K.S. and Larsen, P.R., Eds., Williams Textbook of Endocrinology, 12th Edition, Saunders Elsevier, Philadelphia, Vol. 23, 935-1053. https://doi.org/10.1016/B978-1-4377-0324-5.00024-9

[21] Macdonald, E.M., Koval, J.J., Natale, R., Regnault, T. and Campbell, M.K. (2014) Pop- 
ulation-Based Placental Weight Ratio Distributions. International Journal of Pediatrics, 2014, Article ID: 291846. https://doi.org/10.1155/2014/291846

[22] Gupta, S. and Gupta, P. (2012) Corelation of Placental Weight and Fetal Outcome in Pregnancy Induced Hypertension. Indian Journal of Applied Basic Medical Sciences, 14, 76-82.

[23] Shehata, F., Levin, I., Shrim, A., Ata, B., Weisz, B., Gamzu, R., et al. (2011) Placenta/Birthweight Ratio and Perinatal Outcome: A Retrospective Cohort Analysis. BJOG, 118, 741-747. https://doi.org/10.1111/j.1471-0528.2011.02892.x

[24] Raghavendra, A.Y., Vinay, K.V. and Veena, P. (2014) A Study of Placenta Weight and Foetal Outcome in Different Grades of Pregnancy Induced Hypertension. International Journal of Anatomy and Research, 2, 625-629.

https://doi.org/10.16965/ijar.2014.509

[25] Voldner, N., Qvigstad, E., Froslie, K.F., Godang, K. and Henriksen, T. (2010) Increased Risk of Macrosomia among Overweight Women with High Gestational Rise in Fasting Glucose. The Journal of Maternal-Fetal \& Neonatal Medicine, 23, 74-81. https://doi.org/10.3109/14767050903121472

[26] Roland, M.C.P., Friis, C.M., Voldner, N., Godang, K., Bollerslev, J., Haugen, G., et al. (2012) Fetal Growth versus Birthweight: The Role of Placenta versus Other Determinants. PLoS ONE, 7, e39324. https://doi.org/10.1371/journal.pone.0039324

[27] Risnes, K.R., Romundstad, P.R., Nilsen, T.I., Eskild, A. and Vatten, L.J. (2009) Placental Weight Relative to Birth Weight and Long-Term Cardiovascular Mortality: Findings from a Cohort of 31,307 Men and Women. American Journal of Epidemiology, 170, 622-631. https://doi.org/10.1093/aje/kwp182

[28] Daru, P.H., Egwuda, K., Madziga, I.G., Ocheke, A.N. and Okpe, S.E. (2012) Does the Placental Weight Affect Foetal Outcome Findings from Central Nigeria? Tropical Journal of Obstetrics and Gynaecology, 29, 48-52.

[29] Barker, D.J., Bull, A.R., Osmond, C. and Simmonds, S.J. (1990) Fetal and Placental Size and Risk of Hypertension in Adult Life. BMJ, 301, 259-262.

https://doi.org/10.1136/bmj.301.6746.259

[30] Little, R.E., Zadorozhnaja, T.D., Hulchiy, O.P., Mendel, N.A., Shkyryak-Nyzhnyk, Z.A., Chyslovska, N., et al. (2003) Placental Weight and Its Ratio to Birthweight in a Ukrainian City. Early Human Development, 71, 117-127. https://doi.org/10.1016/S0378-3782(02)00118-4

[31] Afodun, A.M., Ajao, M.S. and Enaibe, B.U. (2015) Placental Anthropometric Features: Maternal and Neonate Characteristics in North Central Nigeria. Advances in Anatomy, 2015, Article ID: 790617. https://doi.org/10.1155/2015/790617

[32] Lao, T.T. and Wong, W.M. (2001) Implications of a High Placental Ratio in Pregnancies with Appropriate-for-Gestational Age Neonates. Gynecologic and Obstetric Investigation, 52, 34-37. https://doi.org/10.1159/000052937

[33] Onankpa, B.O., Airede, K.I., Ahmed, H. and Jiya, N.M. (2006) The Birth Weight of Apparently Healthy Nigerian Newborn in Sokoto. Sahel Medical Journal, 1, 19-22. https://doi.org/10.4314/smj2.v9i1.12919

[34] Ditchfield, A.M., Desforges, M., Mills, T.A., Glazier, J., Wareing, M., Mynett, K., et al. (2015) Maternal Obesity Is Associated with a Reduction in Placental Taurine Transporter Activity. International Journal of Obesity, 39, 557-564. https://doi.org/10.1038/ijo.2014.212

[35] HAPO Study Cooperative Research Group (2010) Hyperglycaemia and Adverse Pregnancy Outcome (HAPO) Study: Associations with Maternal Body Mass Index. BJOG, 117, 575-584. https://doi.org/10.1111/j.1471-0528.2009.02486.x 